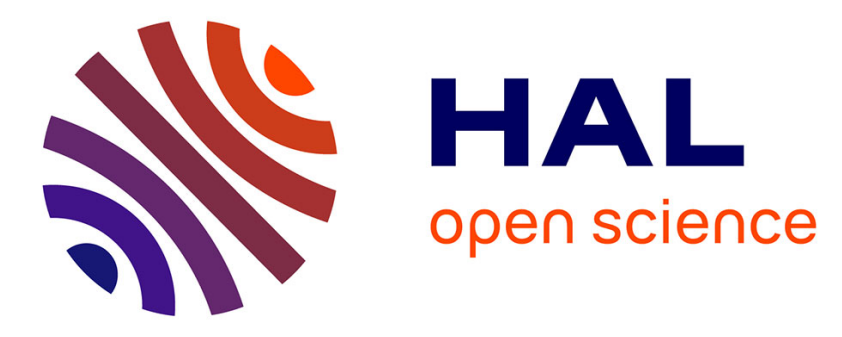

\title{
Virtual Load Machine as Test Environment for Industrial Storage Applications
}

Darian Andreas Schaab, Fabian Zimmermann, Sebastian Weckmann, Alexander Sauer

\section{- To cite this version:}

Darian Andreas Schaab, Fabian Zimmermann, Sebastian Weckmann, Alexander Sauer. Virtual Load Machine as Test Environment for Industrial Storage Applications. IFIP International Conference on Advances in Production Management Systems (APMS), Sep 2017, Hamburg, Germany. pp.213-220, 10.1007/978-3-319-66923-6_25. hal-01666203

\section{HAL Id: hal-01666203 https:/ /hal.inria.fr/hal-01666203}

Submitted on 18 Dec 2017

HAL is a multi-disciplinary open access archive for the deposit and dissemination of scientific research documents, whether they are published or not. The documents may come from teaching and research institutions in France or abroad, or from public or private research centers.
L'archive ouverte pluridisciplinaire HAL, est destinée au dépôt et à la diffusion de documents scientifiques de niveau recherche, publiés ou non, émanant des établissements d'enseignement et de recherche français ou étrangers, des laboratoires publics ou privés.

\section{(c)(1)}

Distributed under a Creative Commons Attribution| 4.0 International License 


\title{
Virtual Load Machine as Test Environment for Industrial Storage Applications
}

\author{
Darian Andreas Schaab 1[0000-0003-0574-4300], Fabian Zimmermann 2[0000-0003-3633-1816], Se- \\ bastian Weckmann ${ }^{2[0000-0003-0918-4953]}$, Alexander Sauer ${ }^{1}$ \\ ${ }^{1}$ Institute for Energy Efficiency in Production, University Stuttgart, 70569 Stuttgart, Germany \\ ${ }^{2}$ Fraunhofer Institute for Manufacturing Engineering and Automation IPA, 70569 Stuttgart, \\ Germany \\ darian.andreas.schaab@eep.uni-stuttgart.de
}

\begin{abstract}
The market share of renewable energy is rising all over the world and leads to a more and more volatile energy supply. The challenge of keeping supply and demand constantly balanced is getting more complex and dynamic. Large scale energy consumers like industrial facilities need to take on an active role in the energy system and adapt their energy consumption to the energy availability. Denoted as energy flexibility this approach controls the energy consumption by changing e.g. the production plan. Storage technologies decouple offer and demand of energy, that end-users are enabled to adapt their energy consumption. Testing new applications for storages can be technologically demanding and is associated with high costs. This paper proposes a hardware in the loop test environment, with which hardware integrations and control strategies of electric storage systems can be tested on a small scale.
\end{abstract}

Keywords: Energy storage, Load flow, Smart grids

\section{Introduction}

Renewable energies increase the share of fluctuating energy supply within the electric grid. New strategies for balancing the grid need to be developed. One approach is an active consumer role, which adapts its consumption to market signals. The major challenge for industrial consumers is to control their power consumption with little impact on manufacturing [1]. Stable power supply is a major requirement for a production site and therefore new solutions for energy distribution on factory level are developed. The energy consumption from the external supply grid can be controlled by an intelligent energy management, that combines private energy generation, energy procurement, energy storage and the production as energy consumer [2]. Major challenges of the smart grid approach is to run the production smoothly and costeffectively as well as to ensure a high security and quality of supply [3]. 


\section{State of the art}

In particular energy storage solutions are a key technology to decouple energy production and consumption within factory. High technological standards for storage solutions in industry, are a major challenge and it is demanding to find an economic application. Current applications of electrochemical energy storages are mainly used to compensate power interruptions and instabilities within the grid [4].

Solutions to shave of power peaks in an industrial environment without the proof of the economic benefit is shown by Putz et al. [5, 6]. The application validates the technical feasibility of supercapacitors within a machine, but the implementation is specifically adapted to a single machine.

In the field of battery research, lifecycle predictions are an important research topic. Fatigue algorithms are used to calculate degradation of battery technologies [7-9]. Commercial battery solutions are tested through standard procedures, which use synthetic load profiles at constant current, load amplitude and temperature [10, 11]. For industrial applications life-cycle evaluations with real load profiles are essential.

A storage needs a converter technology to be embedded into an industrial environment [12]. As these technologies interact between storage and process, they need to be considered in experimental setups for evaluation. Kesler et al. and Jonke et al. show a concepts of an adjustable consumers connected to the electronic grid. These systems can be used to test components connected to an electric grid [13, 14].

In literature a hardware in the loop specifies test environments, with which developed hardware or physical systems are tested through realistic input parameters. In the research area of smart grid technologies implementations and control algorithms are evaluated with hardware in the loop environments $[15,16]$.

\section{Evaluation of newly developed smart grid technologies}

Industrial environments offer a great variety of possible applications for storage systems. Interesting applications within the scope of production planning are process efficiency, process quality and possibilities for decoupling electric load. An optimized operation strategy should allow for the transient load characteristic of each process step. At the grid connection a characteristic load profile of every machine and process can be detected, whereas the overall load within the local grid can be optimized with respect to a variety of objectives [12].

Storage solutions change the power characteristics through a controlled feed-in and feed-out of power. These solutions consist of a control algorithm, a converter technology and the storage. The storage system needs to be profitable as well as technologically save. Simulation tools are on one hand suitable to develop new solutions for a specific application, on the other hand are simulations always limited to the model assumptions. Further challenges within real implementations can only be evaluated on a hardware level.

A platform, which enables testing control algorithms, as well as converter and storage technologies, opens up an intermediate step between simulation and full scale 
field applications and therefore, enables to improve the predictions of simulation models. This work presents a Hardware in the loop test environment, which emulates the power draw and the production behavior of a machine. The system can be configured to emulate a measured load profile and change system states like a real production machine. With the single-machine-test-environment (SMTE) storage applications on a machine level can be analyzed and validated (Fig. 1).

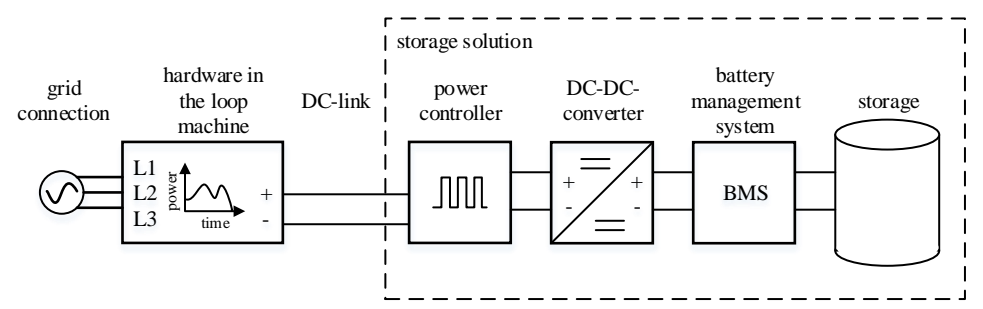

Fig. 1. Single-machine-setup as a test environment for storage solutions.

The developed test environment is appropriate to test control algorithms on a hardware level, examine storage degradation based on real load profiles and the coupling between all hardware components. As a result storage systems within a smart-grid can be evaluated for a variety of production environments.

\section{Design specifications}

The basic idea of the system is to map the load profile of a production machine into an experimental setup. In this scope the SMTE has to represent the energetic as well as the production characteristics. Information about the product type, lot size and operational availability affect the load characteristic of a machine are transferred within production. Different product types change the characteristics through specific process parameters. Lot size affects the grid load through the appearance of downtimes and changeover-times. Furthermore operational availability is the prerequisite for the operation of a machine and the overall equipment effectiveness adds unforeseen interruptions, setup and loading times.

Fig. 2 shows the electric load of the different process steps of an injection moulding machine. As the injection time is an example for a machine parameter, which is specific to the product. Lining-up the different load profiles in order of the process steps result into the product-specific load profile of the machine. Whereas the plasticization time (warm-up, injection), the timeframe for holding pressure, as well as the ejection process vary with each product type.

The proposed hardware in the loop machine will be able to follow a specified production plan. For instance does the schedule plan to produce two lots. The first lot consists of 100 pieces of product A and the second lot consists of 200 pieces of product B. The machine will follow the schedule and simulates the energetic load of the first lot with the process specific parameters for product A. For the changeover to product $\mathrm{B}$ the machine will simulate the power draw of the standby state. Afterwards 
the machine load of the second lot will be simulated with the process specific parameters of product $B$.

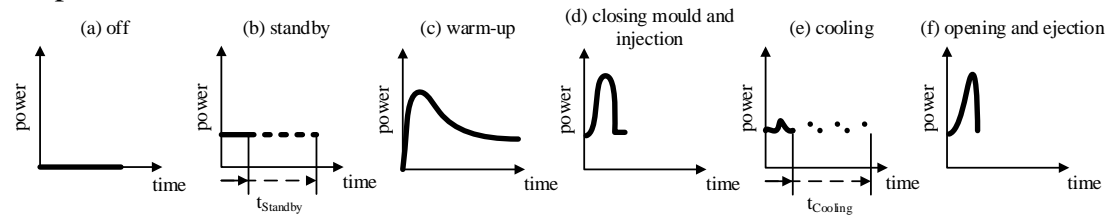

Fig. 2. Showing the specific load profiles separated for different process steps: (a) off, (b) standby, (c) warm-up, (d) closing mould, (e) injection, (f) opening and ejection.

State of the art are two storage topologies. The first possibility is the integration into the DC-link of a production machine and the second possibility is the integration within the AC-grid in front of the rectifier. The planned design opens up the possibility to evaluate both topologies as the SMTE offers a DC-link as well as to a three phase contact.

\section{Design of the hardware concept}

The main function of the machine is a controllable power consumption on a DC-link as well as on a three-phase power connector. The proposed concept consists of an asynchronous machine, which is connected in Y-connection to the grid (Fig. 3). A standard cage induction motor with two poles and a rated power of $750 \mathrm{~W}$ is selected.

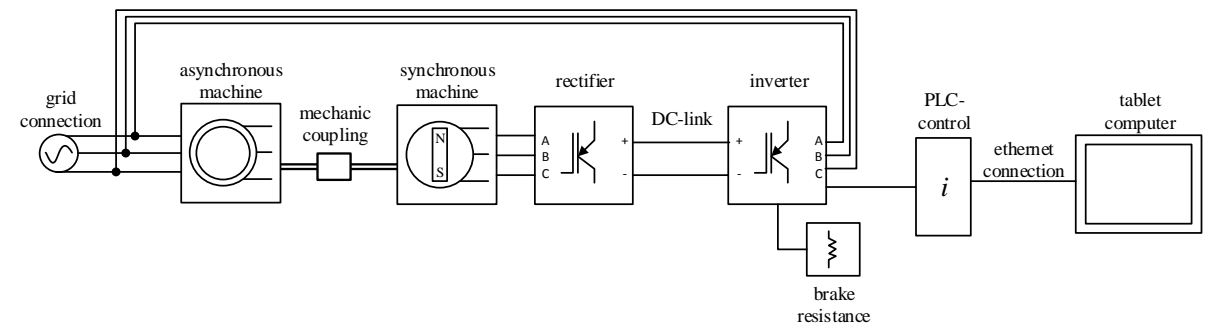

Fig. 3. Design of the planned machine concept to simulate various energetic foot-prints of a production machine.

The asynchronous machine is mechanically coupled to a synchronous servo-motor, which is fed through an inverter. The inverter draws power from a DC-link, which is fed by an unregulated rectifier. State of the art servo-controllers can control the torque of the synchronous machine. With the assumption of negligible losses in the synchronous machine and the power electronics, the mechanical power equals the electrical power drawn by the Inverter. As it is assumed that the asynchronous machine holds the angular velocity $\omega$ of the system stationary. The power-usage of the machine can be controlled by changing the synchronous torque $\tau_{\text {syn }}(1)$.

$$
P_{e l} \approx P_{\text {mech }}=\tau_{\text {syn }} \cdot \omega
$$


The PLC-control calculates the torque input to the inverter from the targeted power, which should be drawn by the SMTE. The machine is controlled through a human machine interface on a tablet computer. Via Ethernet connection the SMTE can be configured and the current machine and production state is changed.

\section{Proof of concept}

Input signals for the SMTE are dynamic and so the operation of the whole system cannot be assumed to be in steady state. A simulation model of the dynamic system is built-up to show the system behavior. The model was build-up in MATLAB Simulink and a reference scenario with an injection molding machine is performed.

\subsection{Simulink model for transient performance}

A given dynamic model of an induction motor from the MATLAB Specialized Technology library is used. The machine is driven by an ideal voltage supply with three phases at $50 \mathrm{~Hz}$. The synchronous machine is wired in a star connection, while the inverter is modeled as an ideal voltage source over the three phases. The torque forming current is controlled by a PI-controller, which is fed with the error value $e(t)$ of the desired torque $\tau_{\text {set }}$ divided by the synchronous motor torque constant $K_{T}$ and the measured q-current $i_{q, i s}(2)$.

A rigid coupling between induction and synchronous machine is assumed, whereas the sum of asynchronous torque $\tau_{a s}$ and synchronous machine torque $\tau_{s y n}$ accelerates an inertia $\Theta$ of $0.0015 \mathrm{kgm}^{2}$ (3).

$$
\begin{gathered}
e(t)=i_{q, i s}-\tau_{s e t} / K_{T} \\
\Theta \dot{\omega}=\tau_{a s}-\tau_{s y n}
\end{gathered}
$$

\subsection{Simulation of an injection molding machine}

For the simulation the load profile of a typical injection molding machine is used. Fig. 4 shows the measured power draw of an injection molding machine. The cycle includes closing the mould, injection of the polymer, holding pressure to compensate shrinkage and ejection of the parts with opening of the mould. The maximum power that can be reached by the SMTE is specified by the power limit of the asynchronous machine. The whole load profile of the injection moulding machine $P(t)$ is scaled down, to match maximum machine power performance. Therefore, the profile is scaled by the maximum measured power value $\max (P(t))$ and the power limit of the asynchronous machine $P_{a s, \max }$ (4). The torque input values of the synchronous machine $\tau_{\text {set }}(t)$ are calculated by dividing the power set points $P_{\text {set }}(t)$ by the nominal rotational frequency of the asynchronous machine $\omega_{a s}(5)$.

$$
P_{\text {set }}(t)=P(t) / \max (P(t)) \cdot P_{a s, \max }
$$




$$
\tau_{\text {set }}(t)=P_{\text {set }}(t) / \omega_{a s}
$$

As the load profile is just a small window of the whole measurement and starts with the first injection, all upstream states are skipped and setpoint value starts an offset of $7 \mathrm{~kW}$. The simulation would start with an unrealistic discontinuity. This discontinuous step needs to be avoided to prevent oscillations. A continuous time series is added to the load profile by adding a linear rise from zero to the first torque value of the measured load profile.

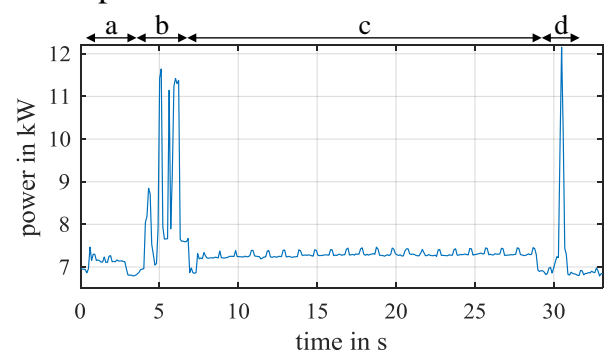

a) standby

b) closing mould \& injection

c) cooling

d) opening and ejection

Fig. 4. Power draw over time for a typical injection molding cycle

\subsection{Results}

The simulation validates the transient performance of the overall system.

a) shows the simulated electrical power of the inverter fed into the synchronous machine in comparison to the specified power value. The deviation in relation to the demanded power is shown in

b). The deviation between simulated and specified power is up to fifteen percent. As the mould is closed the load has a peak, before the injection is a constant load. At the end of the profile the load profile has another peak as the machine builds-up the holding pressure. Afterwards the mould is opened and the parts ejected and the load sinks back to the standby level.

There are three sources of error which cause the deviation in power and torque. The first part is caused by the transfer performance of the control. High frequent peaks are delayed and lead to error in torque. In areas of a high gradient the deviation rises up to eight percent because of the limited dynamic of the electrical machines. The second reason for the deviation is the mechanical inertia of the system, which delays the system response. The third part for error is caused by the set point calculation. The machine follows the specified torque with a constant offset of $1.5 \%$ within the timespan from 13 to $34 \mathrm{~s}$. This deviation can be explained by the neglect of power loss $P_{\text {loss }}$ within the synchronous machine (6). The electrical power of the real system $P_{e l}$ is the sum of mechanical power $P_{\text {mech }}$ and power loss in the synchronous machine and inverter $P_{\text {loss }}(6)$. As the power loss is neglected the calculated set point for the torque is higher than required.

$$
P_{e l}=P_{\text {mech }}+P_{\text {loss }}
$$


The aim of the system is to follow the emulated load profile within an error band of ten percent.

b) shows that the system has a limited dynamic as the desired error band is stridden with high power gradient. The system dynamics can be improved by tuning the control, whereas in future a particular control design will be examined.
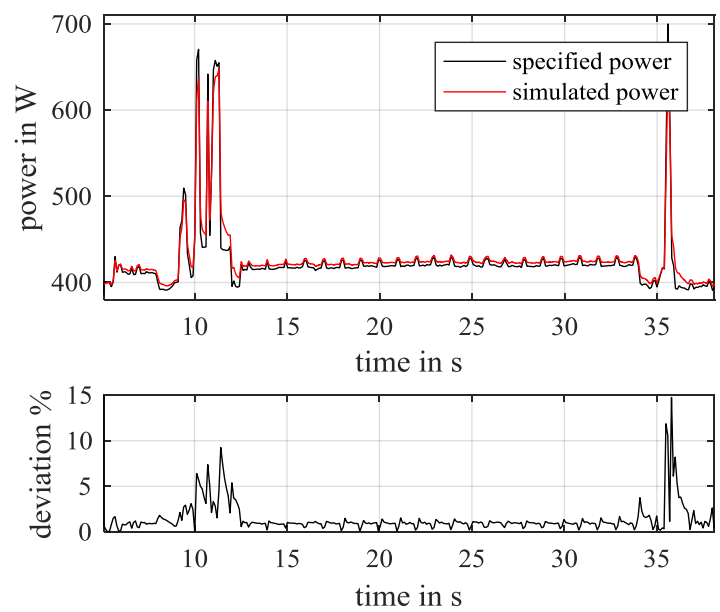

Fig. 5. (a) Comparison of power input versus simulated power draw by the synchronous machine. (b) Deviation between set point and simulated power draw from the synchronous machine.

\section{Conclusion}

The approach of an experimental setup, which represents the performance of a generic production machine is introduced. Modelling the production and energetic characteristics is in focus of the proposed design concept. Different electric loads are emulated by an asynchronous machine with the torque of a servomotor. It is shown how the process of an injection moulding machine can be replicated on the machine in a small power scale. Through evaluation with a transient simulation in MATLAB Simulink it is shown, that the system can be stable controlled by the proposed controller. Dynamic performance of the machine is limited by the controller and the mechanical inertia. Deviations between set output and simulated output are explained. The neglect of losses within the inverter and the synchronous machine leads to a small deviation, which does not put the application of the machine on risk. The proposed system is a major part within the evaluation of storage applications within an industrial smartgrid, as a high variety of scenarios can be run on the same topology. The test environment is appropriate to test control algorithms on a hardware level, examine storage degradation based on real load profiles and the transient coupling between all hardware components. 


\section{References}

1. Weckmann S, Jin H, Sauer A (2016) Demand Side Management: Bewertung von Potenzialen auf Basis des Energiewertstroms. wt Werkstatttechnik online 106(6)

2. Weckmann S, Zimmermann F (2016) Softwarelösungen für das Energiemanagement von morgen: Eine vergleichende Studie, Stuttgart

3. Sauer A, Bauernhansl T (2016) Energieeffizienz in Deutschland: Eine Metastudie - Analyse Und Empfehlungen. Springer-Verlag, Berlin. 978-3-662-48882-9

4. Korthauer R (2013) Handbuch Lithium-Ionen-Batterien. Springer-Verlag, Berlin, Heidelberg. 978-3-642-30653-2

5. Putz M, Blau P, Kolesnikov A et al. (2016) Energy storage in drive systems of servo presses for reduction of peak power and energy recovery. In: 2016 18th European Conference on Power Electronics and Applications (EPE'16 ECCE Europe). IEEE, pp 1-10

6. Putz M, Kolesnikov A, Richter M et al. (2015) The application of double-layer capacitor modules for energy storage devices in production machinery. In: 2015 17th European Conference on Power Electronics and Applications (EPE'15 ECCE-Europe). IEEE, pp 1-10

7. Miner MA (1945) Cumulative fatigue damage. Journal of Applied Mechanics 12(3): A159-A164

8. Palmgren A (1924) Die Lebensdauer von Kugellagern. Z. VDI 68. S339-S341

9. Layadi TM, Champenois G, Mostefai M et al. (2015) Lifetime estimation tool of lead-acid batteries for hybrid power sources design. Simulation Modelling Practice and Theory 54: 36-48. doi: 10.1016/j.simpat.2015.03.001

10. Deutsches Institut für Normen e.V. (2004) Ortsfeste Blei--Akkumulatoren - Teil 21: Verschlossene Bauarten Prüfverfahren(60896-21:2004)

11. Deutsches Institut für Normen e.V. (1984) Akkumulatoren - Prüfungen - Wartungsfreie verschlossene Blei-Akkumulatoren mit Gitterplatten und festgelegtem Elektrolyt(43539-5)

12. Vazquez S, Lukic SM, Galvan E et al. (2010) Energy Storage Systems for Transport and Grid Applications. IEEE Trans. Ind. Electron. 57(12): 3881-3895. doi: 10.1109/TIE.2010.2076414

13. Kesler M, Ozdemir E, Kisacikoglu MC et al. (2014) Power Converter-Based Three-Phase Nonlinear Load Emulator for a Hardware Testbed System. IEEE Trans. Power Electron. 29(11): 5806-5812. doi: 10.1109/TPEL.2014.2301815

14. Jonke P, Stockl J, Ertly H Concept of a three phase AC power source with virtual output impedance for tests of grid connected components: 399-404. doi: 10.1109/SEDST.2015.7315242

15. Griese M, Pawlik T, Schulte T et al. Methods for scaling a physical based CHP model for HIL simulation of smart combined grid systems. In: International ETG Congress 2015; Die Energiewende-Blueprints for the new energy age; Proceedings of, pp 1-8

16. Jeon J-H, Kim J-Y, Kim H-M et al. (2010) Development of Hardware In-the-Loop Simulation System for Testing Operation and Control Functions of Microgrid. IEEE Trans. Power Electron. 25(12): 2919-2929. doi: 10.1109/TPEL.2010.2078518 